\title{
The global distribution of fatal pesticide self-poisoning: Systematic
} review

\author{
David Gunnell*1,2, Michael Eddleston ${ }^{2,3}$, Michael R Phillips ${ }^{4,5,6}$ and \\ Flemming Konradsen ${ }^{2,7}$
}

\begin{abstract}
Address: ${ }^{1}$ Department of Social Medicine, University of Bristol, Bristol, UK, ${ }^{2}$ South Asian Clinical Toxicology Research Collaboration (SACTRC), ${ }^{3}$ Scottish Poisons Information Bureau, University of Edinburgh, Edinburgh, UK, ${ }^{3}$ Beijing Suicide Research and Prevention Center, Beijing Hui Long Guan Hospital, Beijing, China, ${ }^{5}$ Department of Psychiatry, Columbia University, New York, USA, ${ }^{6}$ Department of Epidemiology, Columbia University, New York, USA and ${ }^{7}$ Department of International Health, University of Copenhagen, Copenhagen, Denmark

Email: David Gunnell* - d.j.gunnell@bristol.ac.uk; Michael Eddleston - eddlestonm@yahoo.com; Michael R Phillips - phillipschina@yahoo.com; Flemming Konradsen - f.konradsen@pubhealth.ku.dk

* Corresponding author
\end{abstract}

Published: 2 I December 2007

BMC Public Health 2007, 7:357 doi:10.1 | 86/ | 47/-2458-7-357
Received: 24 August 2007

Accepted: 21 December 2007

This article is available from: http://www.biomedcentral.com/I47/-2458/7/357

(c) 2007 Gunnell et al; licensee BioMed Central Ltd.

This is an Open Access article distributed under the terms of the Creative Commons Attribution License (http://creativecommons.org/licenses/by/2.0), which permits unrestricted use, distribution, and reproduction in any medium, provided the original work is properly cited.

\begin{abstract}
Background: Evidence is accumulating that pesticide self-poisoning is one of the most commonly used methods of suicide worldwide, but the magnitude of the problem and the global distribution of these deaths is unknown.

Methods: We have systematically reviewed the worldwide literature to estimate the number of pesticide suicides in each of the World Health Organisation's six regions and the global burden of fatal self-poisoning with pesticides. We used the following data sources: Medline, EMBASE and psycINFO (1990-2007), papers cited in publications retrieved, the worldwide web (using Google) and our personal collections of papers and books. Our aim was to identify papers enabling us to estimate the proportion of a country's suicides due to pesticide self-poisoning.
\end{abstract}

Results: We conservatively estimate that there are 258,234 (plausible range 233,997 to 325,907) deaths from pesticide self-poisoning worldwide each year, accounting for $30 \%$ (range $27 \%$ to $37 \%$ ) of suicides globally. Official data from India probably underestimate the incidence of suicides; applying evidence-based corrections to India's official data, our estimate for world suicides using pesticides increases to 371,594 (range 347,357 to 439,267 ). The proportion of all suicides using pesticides varies from $4 \%$ in the European Region to over $50 \%$ in the Western Pacific Region but this proportion is not concordant with the volume of pesticides sold in each region; it is the pattern of pesticide use and the toxicity of the products, not the quantity used, that influences the likelihood they will be used in acts of fatal self-harm.

Conclusion: Pesticide self-poisoning accounts for about one-third of the world's suicides. Epidemiological and toxicological data suggest that many of these deaths might be prevented if (a) the use of pesticides most toxic to humans was restricted, (b) pesticides could be safely stored in rural communities, and (c) the accessibility and quality of care for poisoning could be improved. 


\section{Background}

The World Health Organisation (WHO) estimated that there were 873,000 suicides worldwide in 2002[1] which makes suicide a major cause of premature mortality globally. A central component of suicide prevention strategies is restricting access to lethal means [2]; this is because impulsive acts of self-harm in persons with a low intent to die may, nevertheless, be fatal if high-lethality methods are easily accessible $[3,4]$. It is therefore important to identify the most commonly used methods of suicide worldwide both to formulate appropriate strategies for restricting access to highly-lethal methods and to improve the ability of health care systems to effectively treat individuals who use these methods

Based on studies carried out in Sri Lanka, in 1984 Jeyaratnam estimated there were 220,000 pesticide related deaths every year worldwide, most of which were suicides [5]. Recent extrapolations of data from a few countries in Asia suggest that there may be 300,000 suicides by deliberate ingestion of pesticides annually in this region alone[6,7]. The WHO reports that pesticides are now the most common method of suicide worldwide[8].

The most likely explanation for the high numbers of pesticide suicides in developing countries is the high case fatality associated with pesticide ingestion compared to the relatively low case fatality of many of the substances commonly taken in acts of self-poisoning in the West. For example case fatality among persons admitted to hospital for treatment of self-poisoning in England and Wales is $<0.5 \%$ [9] but in rural areas of Sri Lanka it is 7\%[10]. Selfpoisoning with some commonly used pesticides is particularly lethal - case-fatality following paraquat and aluminium phosphide ingestion is in excess of $70 \%[11,12]$.

To date efforts to estimate the international burden of pesticide suicides have been based on relatively crude extrapolations from studies carried out in one or two countries[5-7]. The aim of this paper is to systematically review the world literature on the use of pesticides for suicide and, using the data retrieved, to estimate the number of pesticide suicides worldwide and in each of the WHO's six regions. For the purpose of this review we define pesticides as chemical products used for the control of unwanted animals, plants and fungi - primarily rodenticides, insecticides, weedicides and fungicides.

\section{Methods}

\section{Data sources}

A systematic search of Medline, Psyc-INFO and Embase databases for papers published between 1990 and 2007 documenting the use of pesticides for fatal and non-fatal self-harm was supplemented by an internet-based search (using Google) for national and international data on: (a) estimated total suicides; (b) estimated suicides by pesticide poisoning and (c) national population estimates.

For our searches of Medline, PsycINFO and EMBASE we used the following search terms coded in all fields (af) for the years January 1990 - June 2007: (Pesticide? or insecticide? or rodenticide? or paraquat or organophosphate? or organophosphorus.af or agricultural.af or agrochemical?).af and (suicid??.af or (self and harm).af or parasuicide.af or (Self-Injurious and Behavior).af or ((self?.af or deliberate.af) and poison???.af)). We did not restrict our search to English language papers, but only reviewed papers in other languages if they had English language abstracts.

In our internet searches we particularly focused on identifying data for those countries in each of the six WHO regions that are likely to make the greatest contribution to the world burden of pesticide suicides because of their large populations: Nigeria and Ethiopia (Africa); United States of America, Brazil and Mexico (the Americas); Pakistan, Iran and Egypt (Eastern Mediterranean); The Russian Federation, Turkey and Germany (Europe); India, Indonesia, and Bangladesh (South East Asia); China and Japan (Western Pacific). We also retrieved potentially relevant publications cited in retrieved articles and searched our personal reference collections and books for potentially relevant material.

We also identified data on the use of pesticides for nonfatal acts of self-poisoning, but these data were not used to estimate suicides for each region.

\section{Data synthesis}

Data from all relevant articles were abstracted by DG. Suicide data for the six WHO regions were obtained from the 2004 World Health Report [1]. In this report countries in each of the six WHO regions are categorised into five mortality strata depending on levels of child and adult mortality [Stratum A: Very low child, very low adult mortality; Stratum B: Low child, low adult mortality; Stratum C: Low child, high adult mortality; Stratum D: high child, high adult mortality; Stratum E: High child, very high adult mortality][1]. Estimates of the number of suicides within each stratum are recorded by WHO.

We assumed the proportion of all suicides due to pesticides in each country within a regional mortality stratum is similar, so we estimated the percentage of suicides due to pesticides within each mortality stratum for each of the six regions based on those countries for which we identified data in our searches. Where several sources of data are available for a single country we selected the most geographically comprehensive data, or if several such sources existed we used the most recent data. Where there were 
data for several countries within a stratum, we pooled these estimates weighting them according to the size of the populations (source: WHO World Health Report 2004[1]) of the contributing countries. Thus if data were available from four countries within a stratum, and those country's populations were 4.5 million, 3 million, 2 million and 0.5 million we gave a weight of 0.45 to the estimate from the largest country and only 0.05 to the estimate from the smallest country. Where data were available for only one country within a stratum, we calculated $95 \%$ confidence intervals around our estimate for that stratum based on the $95 \%$ confidence intervals for the estimate from the relevant country. Where data for several countries were used for our estimate, we used data from the country reporting the lowest proportion of pesticide suicides for the lower limit of our plausible range and that reporting the highest proportion for the upper limit. Where data on total pesticide suicides were given without a denominator for total suicides in that country, we obtained data on overall suicides from the WHO's Statistical Information System 108] for the relevant or closest years. For Jordan, the only country with pesticide suicide data in the Eastern Mediterranean-B stratum, no data on the total number of suicides (all methods) were available from WHO. In this stratum our estimates were derived by applying Jordan's overall pesticide suicide rate to the region's population and dividing this figure by WHO's estimate for the region's total number of suicides.

To estimate the global burden of pesticide suicides we summed total pesticide suicides for each regional mortality stratum. For the plausible range for the world total we summed totals for the lower and upper plausible estimates for each regional stratum.

In view of concerns about the reliability of national suicide data from India, we carried out a sensitivity analysis using literature-based estimates of India's suicide rate and of the proportion of suicides due to pesticides.

\section{Results}

Our final estimate of the global pesticide suicides is based on data extracted from 25 of the 343 papers and reports (Figure 1) retrieved for detailed evaluation. Table 1 presents summary data for overall and pesticide suicides for the mortality strata for each of WHO's six regions.

\section{Africa (Figure 2)}

Data on suicide and the methods used for suicide on the African continent are sparse. For those countries where the substances taken in episodes of self-poisoning have been documented, there appears to be considerable variability in the contribution of pesticide poisoning. Data on hospital admissions (fatal and non-fatal) for self-poisoning indicate that pesticides were used in $46 \%$ of episodes in
Kampala (Uganda) in 2002,[13] about 50\% in Nairobi (Kenya, 1980-3) [14], 3\%-30\% in Nigeria in the 1970s80s [15-17], about $40 \%$ in the major hospitals in Zimbabwe in the 1980s and 90s $[18,19]$, and about $50 \%$ in Ethiopia in the early 1980 s $[20,21]$.

Our pesticide mortality estimate for Africa is based on data from four studies carried out in mainly urban regions within Nigeria (Stratum-B), South Africa (Stratum-E), Tanzania (Stratum-E), and Malawi (Stratum-E). These four countries comprise $32 \%$ of the region's population. Autopsy data for the Ile Ife region of Nigeria (1979-1988) suggest that a single pesticide (the organochlorine, lindane) accounted for $32 \%(n=21)$ of the region's 65 suicides[22]. Only $1 \%(13 / 1018)$ of suicides in Durban, South Africa in 1997-2002[23]) employed pesticides; $12 \%(12 / 100)$ of suicides in Dar es Salaam, Tanzania in 2001-2 employed pesticides [24]; and 79\% (66/84) of suicides in Malawi in 2000-3 employed pesticides[25]. Based on these data the weighted estimate of the proportion and number of suicides that employed pesticides in Africa is $22.9 \%$ and 7,800 (plausible range: from 5,200 to 21,910).

\section{The Americas (Figure 3)}

Pesticides are rarely used in acts of self-harm in North America. In the USA they were used in 87 suicides between 1995-1998 (approximately 22 per year)[26]. We found no data on the use of pesticides for suicide in Canada.

Grouped data for total pesticide deaths (suicide and nonsuicide) were available for a number of Central American countries. Epidemiological surveillance data for Belize, Costa Rica, El Salvador, Guatemala, Honduras, Nicaragua and Panama indicate there were 748 pesticide related deaths in these countries in 2000[27]. If these data are correct, and the deaths are mainly suicides, then based on WHO suicide statistics for these countries $(2,407$ suicides based on an extrapolation of WHO data for 6 of these 7 countries), then pesticides account for $31 \%$ of suicides in this region. This figure contrasts with national suicide mortality data for Mexico, the largest country in Central America, indicating that poisoning (all substances) accounts for $5.9 \%$ of male and $27.5 \%$ of female suicides [28]; although in one area of rural Mexico death rates from paraquat poisoning in 1988-90 were around 2 per 100,000 per year [29]. In contrast, data from Barbados[30], Trinidad[31] and Jamaica[32]indicate pesticides account for a high proportion of suicides in those countries (see Figure 3).

Data for suicide using pesticides in South America are sparse. National statistics for the largest country in the region, Brazil (population 176 million) indicate there 


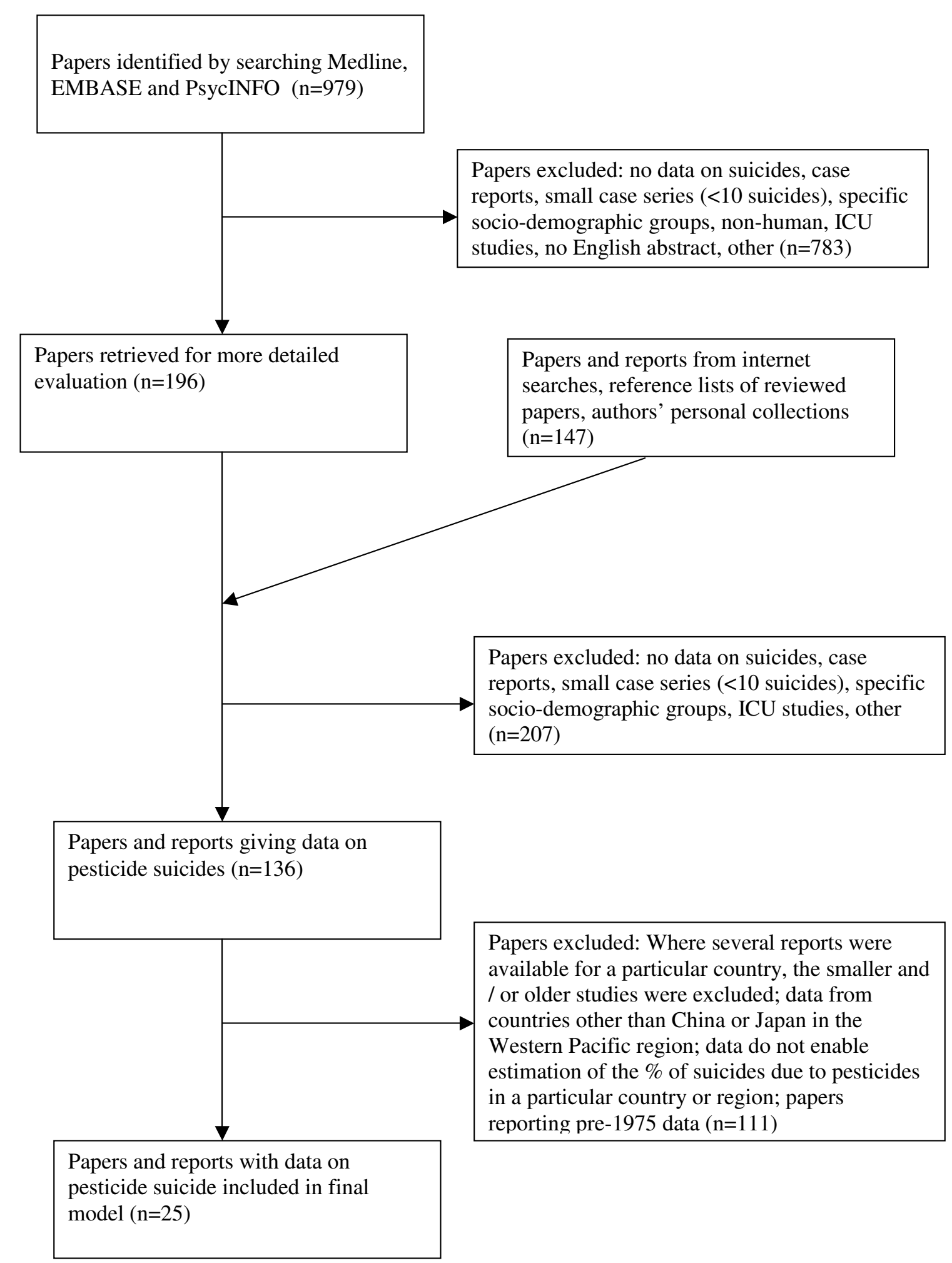

Figure I

Flow diagram for data extraction. 
Table I: Estimates and plausible ranges of pesticide suicides in each of WHO's six regions

\begin{tabular}{|c|c|c|c|c|c|c|}
\hline Region & Stratum & $\begin{array}{l}\text { Population } \\
\text { (millions) } \\
\text { (source: [I]) }\end{array}$ & $\begin{array}{l}\text { Total suicides } \\
\text { (source: }[I] \text { ) }\end{array}$ & $\begin{array}{l}\text { Pesticide suicides } \\
\text { (\% of all suicides) }\end{array}$ & $\begin{array}{l}\text { Plausible range of } \\
\text { pesticide suicides }\end{array}$ & Sources \\
\hline \multirow[t]{2}{*}{ Africa } & $\mathrm{D}$ & 311 & 15,000 & $4,950(33 \%)$ & 3,300 to $6,900 \dagger$ & [22] \\
\hline & $E$ & 361 & 19,000 & $2,850(15 \%)$ & 1,900 to 15,010 & {$[23][24][25]$} \\
\hline Sub-total (Africa) & & & 34,000 & 7,800 (22.9\%) & 5,200 to 21,910 & \\
\hline \multirow[t]{3}{*}{ The Americas } & $A$ & 336 & 35,000 & $25(0.07 \%)$ & 14 to $35^{\dagger}$ & {$[26]$} \\
\hline & B & 445 & 26,000 & $2,860(11 \%)$ & 1,820 to 8,060 & {$[27][33][36]$} \\
\hline & $\mathrm{D}$ & 74 & 2,000 & $220(11 \%)$ & 140 to 620 & {$[27][33][36]$} \\
\hline Sub-total (the Americas) & & & 63,000 & $3,105(4.9 \%)$ & 1,974 to 8,715 & \\
\hline \multirow[t]{2}{*}{ Eastern Mediterranean } & B & 143 & 9,000 & $629(7 \%)$ & 501 to $772 \dagger$ & [38] \\
\hline & $\mathrm{D}$ & 360 & 25,000 & $5,000(20 \%)$ & 4,000 to $6,250^{\dagger}$ & {$[4 I]$} \\
\hline Sub-total (E. Med.) & & & 34,000 & $5,629(16.5 \%)$ & 4,501 to 7,022 & \\
\hline \multirow[t]{3}{*}{ Europe } & A & 415 & 48,000 & $2,400(5 \%)$ & 14 to 4,800 & $\begin{array}{c}{[46][47][48]} \\
{[50]}\end{array}$ \\
\hline & B & 223 & 23,000 & $920(4 \%)$ & 18 to 1,610 & $\begin{array}{c}{[52][53][54]} \\
{[55][56]}\end{array}$ \\
\hline & C & 240 & 92,000 & $2,760(3 \%)$ & $\mathrm{I}, 840$ to $2,760 \dagger$ & [57] \\
\hline Sub-total (Europe) & & & 163,000 & $6,080(3.7 \%)$ & 1,872 to 9,170 & \\
\hline \multirow[t]{2}{*}{ South East Asia } & B & 298 & 37,000 & $9,250(25 \%)$ & 5,920 to 19,980 & {$[62][63]$} \\
\hline & $\mathrm{D}$ & 1,293 & 209,000 & $4 \mathrm{I}, 800(20 \%)$ & 41,800 to 62,700 & $\begin{array}{l}\text { Table } 2 \text { and } \\
{[58]}\end{array}$ \\
\hline Sub-total (SE Asia) & & & 246,000 & $5 I, 050(20.7 \%)$ & 47,720 to 82,680 & \\
\hline \multirow[t]{2}{*}{ Western Pacific } & A & 155 & 35,000 & $\mathrm{I}, 050(3 \%)$ & $\mathrm{I}, 050$ to $\mathrm{I}, 050$ & [68] \\
\hline & B & 1,562 & 296,000 & $183,520(62 \%)$ & 171,680 to 195,360 & [70] \\
\hline Sub-total (W Pacific) & & & 331,000 & $184,570(55.8 \%)$ & 172,730 to 196,410 & \\
\hline Overall Total & & 6,225 & 873,000 & $258,234(30 \%)$ & $\begin{array}{c}233,997(27 \%) \text { to } \\
325,907(37 \%)\end{array}$ & \\
\hline $\begin{array}{l}\text { Total including more } \\
\text { realistic estimate for total } \\
\text { and pesticide suicides in SE } \\
\text { Asia - D }(n=504,800) *\end{array}$ & & & $I, 18 I, 200$ & 37 I,594 (3I\%) & $\begin{array}{c}347,357(29 \%) \text { to } \\
439,267 \text { (37\%) }\end{array}$ & \\
\hline
\end{tabular}

*Assuming $30 \%$ of these are due to pesticides.

tPlausible range based on $95 \%$ confidence intervals around the proportion of suicides due to pesticides in the country whose data were used for estimate in this stratum

were 553 suicide deaths from pesticides in 2004 (accounting for approximately $6.9 \%$ of all suicides)[33]. Other data from Brazil suggest this figure may be an underestimate. In one study over half of all hospital admissions for self-harm to a General Hospital in Rio de Janeiro had taken pesticides[34]. Data for rural areas of Ecuador (5 pesticide suicides) [35] and Suriname (10 out of 20 suicides employed pesticides)[36] indicate that a high proportion of suicides in these areas employ pesticides. Jors et al.[37] cite an MSc thesis indicating that pesticides are the most commonly used method for self-harm in La Paz, Bolivia.

Our estimates of pesticide suicide in the Americas are based on data from the USA (stratum A), Brazil (stratum B), Suriname (stratum B) and the Central American Isthmus (stratum B), countries comprising $59 \%$ of the population of the region $[26,33,36,27]$. We had no specific data for pesticide suicides in countries in Americas stra-
tum-D, but the data from the Central American Isthmus [27] included two stratum-D countries (Guatemala and Nicaragua) so we used data from Americas stratum-B for our estimates for stratum-D. The weighted proportion and number of suicides that employ pesticides in the Americas is $4.9 \%$ and 3,105 (plausible range: 1,974 to 8,715 ).

\section{Eastern Mediterranean Region (EMR) (Figure 2)}

Few publications have presented data on suicide by pesticide poisoning in Eastern Mediterranean countries, where the WHO estimates that there are 34,000 suicides annually. In Jordan (population 5.1 million 1999-2002) - the only country in the EMR-B stratum with national pesticide suicide data - there were 90 pesticide suicides between 1999-2002, resulting in an estimated suicide rate by pesticide ingestion of 0.44 per 100,000[38]. Applying these rates to the population of EMR-B gives an estimated 629 suicides annually for this stratum i.e. $7 \%$ of all suicides. Data for poisoning (deliberate and accidental) in Iran, the 
most populous country in the EMR-B stratum, support the view that pesticides are likely to make an important contribution to mortality from suicide in that country $[39,40]$.

Pesticide suicide data for the EMR-D stratum are only available for Pakistan, which comprises approximately $40 \%$ of the population of this stratum. The only national source of data on suicide methods identified was a review of newspaper reports based on police inquiries in Pakistan 1996-7 [41]: poisons were used in 39\% of the 306 reported suicides and the authors state that organophosphorus pesticides and other agricultural chemicals were the main poisons used. This assertion is supported by findings from the Aga Khan University Hospital in Karachi, Pakistan indicating that between 1989-1995 organophosphorus pesticide poisoning accounted for $21 \%$ of self-harm admissions[42]. But lower estimates come from a series of 98 suicides in Faisalabad, Pakistan in 19982001 in which self-poisoning (all poisons) accounted for only $15 \%$ of deaths [43]. The only data we identified for Egypt came from a study of 200 episodes of hospital-presenting self-harm in Cairo in 1979: 10\% of the episodes used poisons and disinfectants; organophosphates were the most frequently used poisons [44].

Our model estimates of pesticide suicides in the EMR were based on data from Jordan (stratum B)[38] and Pakistan (stratum D) [41] alone, countries comprising 31\% of the population of the region. We assumed half of the poisoning suicides in Pakistan were due to pesticides and so estimated that $20 \%$ of suicides in EMR stratum-D were the result of pesticide ingestion. Overall in the Eastern Mediterranean region the weighted estimate of the proportion and number of pesticide suicides is $16.5 \%$ and 5,629 . Based on confidence intervals around data for Jordan and Pakistan the plausible range for this estimate is 4,501 to 7,022.

\section{Europe (Figure 4)}

Pesticides are infrequently used in acts of self-harm in Europe. The WHO multi-centre study of self-harm in Europe (1982-1993) found that pesticides and agricultural chemicals were used in only $3 \%$ of all episodes reported by the 14 centres [45]. Hungary was an exception to this pattern; in the town of Szeged around $17 \%$ of selfharm episodes involved pesticides [45].

Few publications present national data on the use of pesticides for suicide in Europe. We found no data for either the largest country in Europe - the Russian Federation (population 144 million) or the second largest country, Germany (population: 82 million). Our estimates for the Europe-A stratum were based on data for England \& Wales, Ireland, Sweden, Greece and Spain [46-51]; the
Europe-B stratum on data from Turkey [52], Poland $[53,54]$, Romania[55], and Bulgaria [56]; and stratum-C on data from Hungary [57].

For Europe-A stratum there were estimates of pesticide suicides from rural areas of Spain[51] and Greece [50,49]; to avoid placing too much weight on rural areas, we used the lower estimate - 10\% (9/90) based on data from north west Greece [50]. National data from England \& Wales, Ireland and Sweden suggest a lower incidence in countries within this stratum. In England and Wales 0.5\% ( $n=39$ ) of the approximately 7,843 suicides in 1990-1 were pesticide ingestions[46]. Data for Ireland are restricted to suicide by paraquat ingestion in the agricultural sector; at least $2.0 \%(\mathrm{n}=82)$ of the approximately 3860 suicides in Ireland between 1982-1994 took paraquat [47]. Two of the $7006(0.03 \%)$ suicides in Sweden 1990-1994 employed pesticides [48].

For Europe-B, data from the Trakya region of Turkey (1994-2004) suggest that $7 \%(10 / 137)$ of suicides employed pesticides [52]. The proportion is lower in Romania [55] where 1\% $(104 / 9,660)$ of suicides between 1990-1993 employed pesticides. Data from a region with approximately $8.8 \%$ of Bulgaria's population suggests that pesticides accounted for 78 poisoning deaths (suicide and accident) between 1990-98 (9 per year). Extrapolating these data to the whole of Bulgaria we estimate that $6.8 \%$ of Bulgaria's 12,990 suicides involve pesticide ingestion. Data from Poland for 2000-2002 indicate there were 22 pesticide-associated deaths amongst the country's 24,895 suicides over this period $(0.09 \%)[53,54]$.

Data from Hungary (Stratum-C) indicate that around 2\% (75/2979) of suicides employ pesticides [57].

Our estimate for Europe is based on data from countries comprising approximately 30\% of the region's population. The weighted estimate for the proportion and annual number of pesticide suicides in Europe is 3.7\% and 6,080 (plausible range 1,872 to 9,170 ).

\section{South East Asia (Figure 5)}

Estimates for pesticide suicides in South East Asia are dominated by patterns of suicide in India (SE Asia mortality stratum D), whose population (1,050 million) accounts for $81 \%$ of the 1,293 million people living in stratum-D of the region. Official data for 2005 suggest that $19.6 \%(n=22,327)$ of India's 113,914 officially recorded suicides were self-poisonings with insecticides[58]. A particular feature of self-poisoning in northern India is the frequent ingestion of aluminium phosphide, a fumigant used to protect grain stores, with an associated case fatality in excess of 70\% [12]. The WHO estimate that $55 \%$ of suicides in Bangladesh (SE Asia-D), 


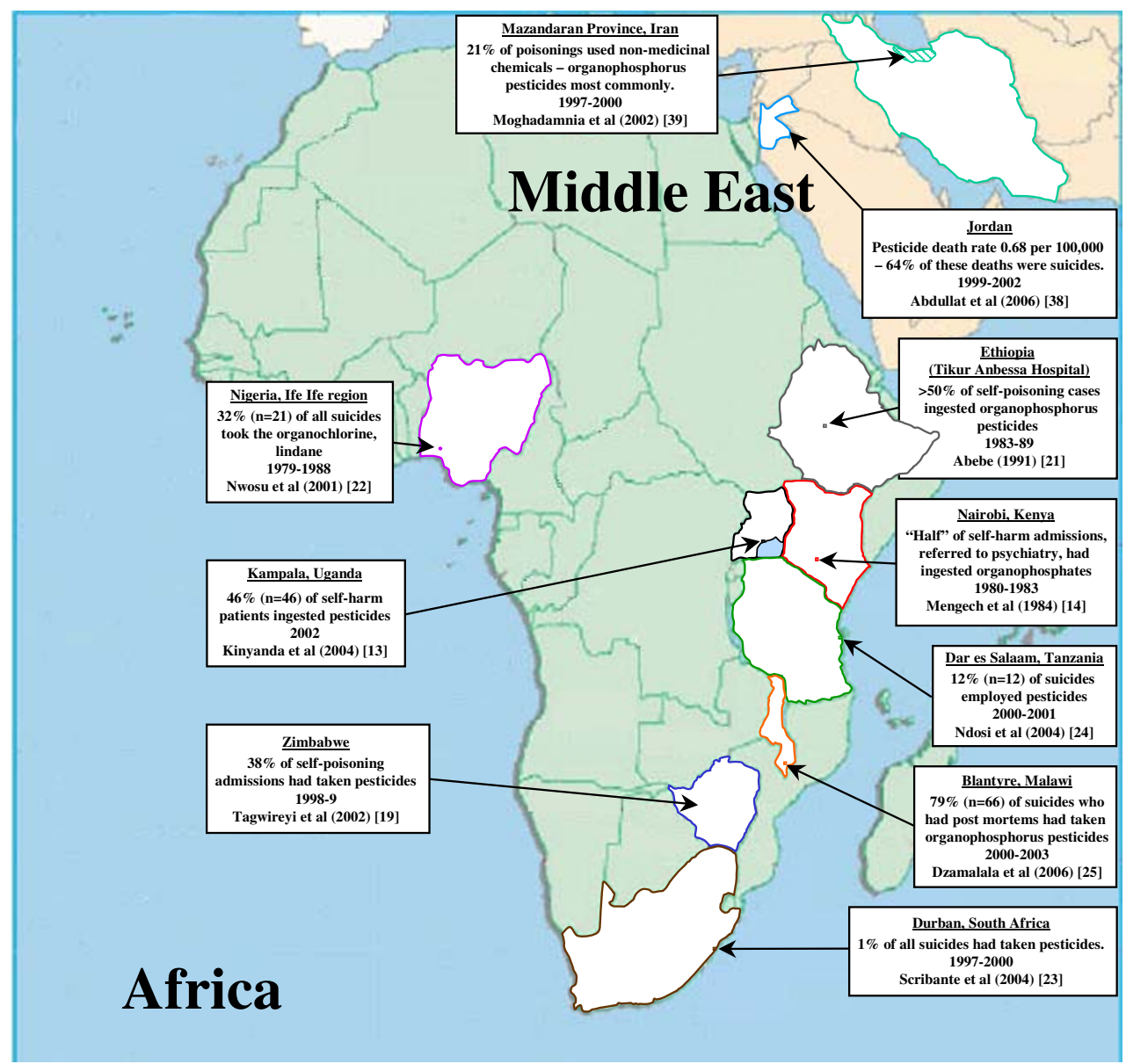

Figure 2

Pesticide suicides in Africa and the Middle East.

the third most populous country in this region (population 144 million), are by self-poisoning[59]. Data from other sources indicate that a large proportion of these fatal poisonings are pesticide ingestions [60,61]. Our estimates for stratum-D are based on official suicide statistics from India[58] and, using data presented in Table 2, an estimated range in the proportion of suicides that employ pesticides in India of $20 \%$ to $30 \%$.

The only countries in the SE Asia-B stratum with data on the proportion of suicides due to pesticides are Sri Lanka and Thailand. National mortality data from Sri Lanka indicate that $54 \%$ of suicides in that country were by pesticide ingestion in 2005 [62]. National data from Thailand (1998-2003) indicate that approximately $16 \%$ of suicides died from agricultural chemical poisoning[63].

Combining the data described above, the weighted estimate for the proportion and annual total of pesticide sui- cides in this region is $20.7 \%$ and 51,050 , with a plausible range of 47,720 to 82,680 . This estimate is based on data from countries comprising $71 \%$ of the population of the region.

The official suicide rate for India (10.3 per 100,000 in 2005[58]) is thought to be an under-estimate. Detailed studies in several regions (Table 2) suggest that India's suicide rates may be as high as 40 per 100,000 and that $30 \%$ or more of these deaths are due to pesticide self-poisoning. The studies reporting the highest suicide rates within India $(>60$ per 100,000$)$ were carried out in rural Tamil Nadu [64-67]. Rates from these studies are three times higher than the official figures for Tamil Nadu[58]. Whilst some of the discrepancies between official suicide rates and those identified in local studies may be due to urbanrural differences in suicide incidence, police data suggest that around $90 \%$ of suicides in India occur outside cities[58]. It therefore seems appropriate to give more weight 


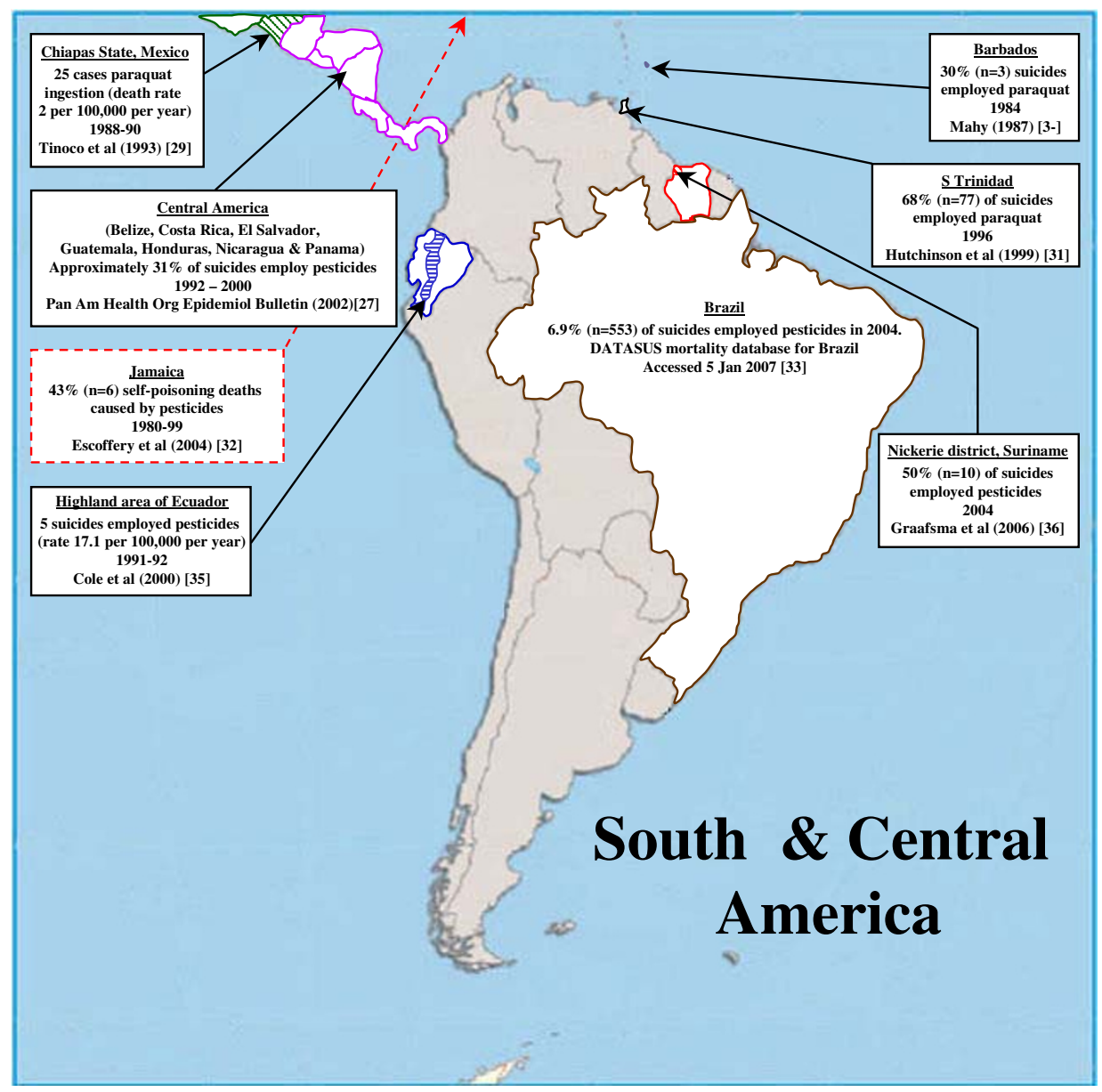

Figure 3

Pesticide suicides in Central and South America.

to estimates derived from rural populations. Using these data we estimate that there may be up to 420,000 suicides in India - 126,000 from pesticide self-poisoning. Applying the estimated suicides rates and proportion of pesticide suicides derived from Table 2 to the whole population of SE Asia D (1,293 million) yields a total of 517,200 suicides (i.e. an additional 308,200 above the official estimate of 209,000 ) and 155,160 pesticide suicides (i.e. an additional 113,360 pesticide suicides). These figures result in a revised estimate of pesticide suicides in this region of 164,410 .

\section{Western Pacific Region (Figure 5)}

Japan's population (127 million) comprises over $80 \%$ of the people in the WPR-A stratum and China's population (1,302 million) comprises over $80 \%$ of the WPR-B stratum. Estimates of pesticide suicides for these two countries alone were used to derive figures for the Western pacific region and sensitivity analyses were based on 95\% confidence intervals around estimates of the proportion of suicides due to pesticides. Japanese national data indicate that $2.4 \%$ of the 22,402 male suicides and $3.7 \%$ of the 9,011 female suicides in 1999 were due to pesticide self-poisoning [68]; 3\% of all suicides were due to pesticides. Applying this proportion to the WPR-A stratum we estimate that 1050 suicides are due to pesticide poisoning.

Pesticides are commonly taken in acts of self-poisoning in China. A study carried out in Northern China indicated that $28 \%$ of 14,771 emergency room visits for self-harm were due to pesticide ingestion[69]. A detailed study of a representative sample of 519 suicides from 23 sites in China (20 rural/3 urban) in 1998-2000 [70] found that $62 \%(323 / 519 ; 95 \%$ CI $58 \%$ to $66 \%)$ were the result of self-poisoning with agricultural chemicals or rat poison. Such high use of pesticides in acts of self-harm is confirmed by studies in Malaysia, where in one region pesticides accounted for $>90 \%$ of suicides between 1973- 


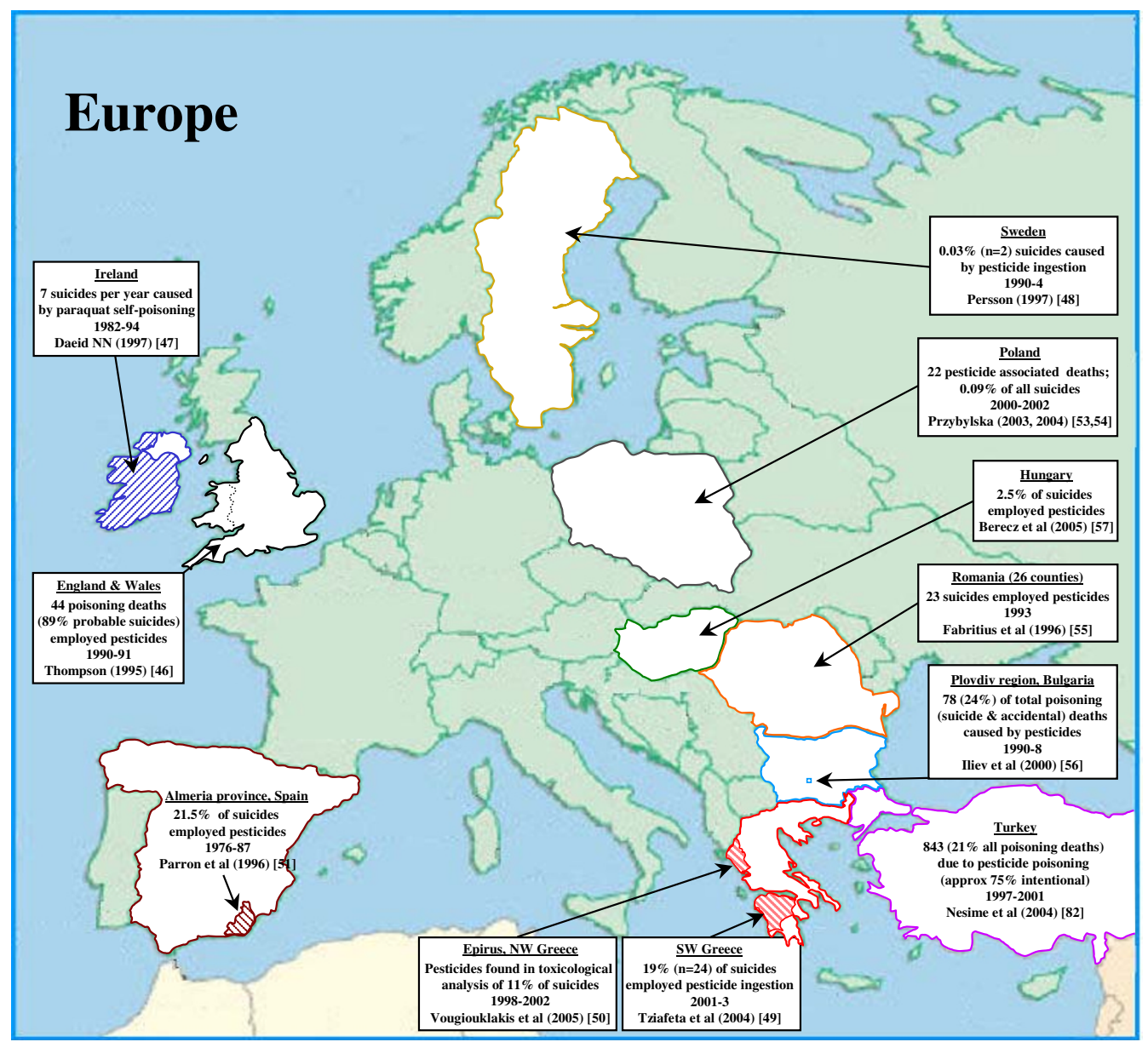

Figure 4

Pesticide suicides in Europe.

84[71]. Recently published national data for Malaysia show that pesticides accounted for 605 deaths (mostly self-inflicted) amongst people admitted to hospital for poisoning between 1999-2001[72]. In South Korea over $20 \%$ of all suicides are due to self-poisoning with pesticides [73]. Using data from Japan (Stratum A) and China (Stratum B) our estimate of the proportion and number of pesticide suicide deaths in the Western Pacific Region is $55.8 \%$ and 184,570 , with a plausible range of 172,730 to 196,410 .

\section{World total}

Combining data from all six regions our best estimate of the annual number of pesticide suicides worldwide is 258,234 with a plausible range of 233,997 to 325,907 . This accounts for $30 \%$ (range $27 \%$ to $37 \%$ ) of all suicides globally. If higher estimates of suicides in India are included in the model the total annual number of world suicides increases from 873,000 to $1,181,200$, the estimated number due to pesticides becomes 371,594 $(347,357$ to 439,267$)$ and the proportion of global suicides due to pesticide ingestion becomes 31\% (29\% to $37 \%)$.

\section{Discussion \\ Main findings}

We conservatively estimate that approximately one third ( $\mathrm{n}=258,234)$ of the world's 873,000 suicides in 2002 were caused by pesticide ingestion. Our estimate may well be too low, since it is influenced by the reliability of official suicide statistics for India. Recent detailed studies of rural India suggest that the true number of suicides may be 2-3 fold higher than official estimates and concentrated in rural areas where pesticide poisoning is common $[67,64]$ a pattern that is also found in China [74]. 


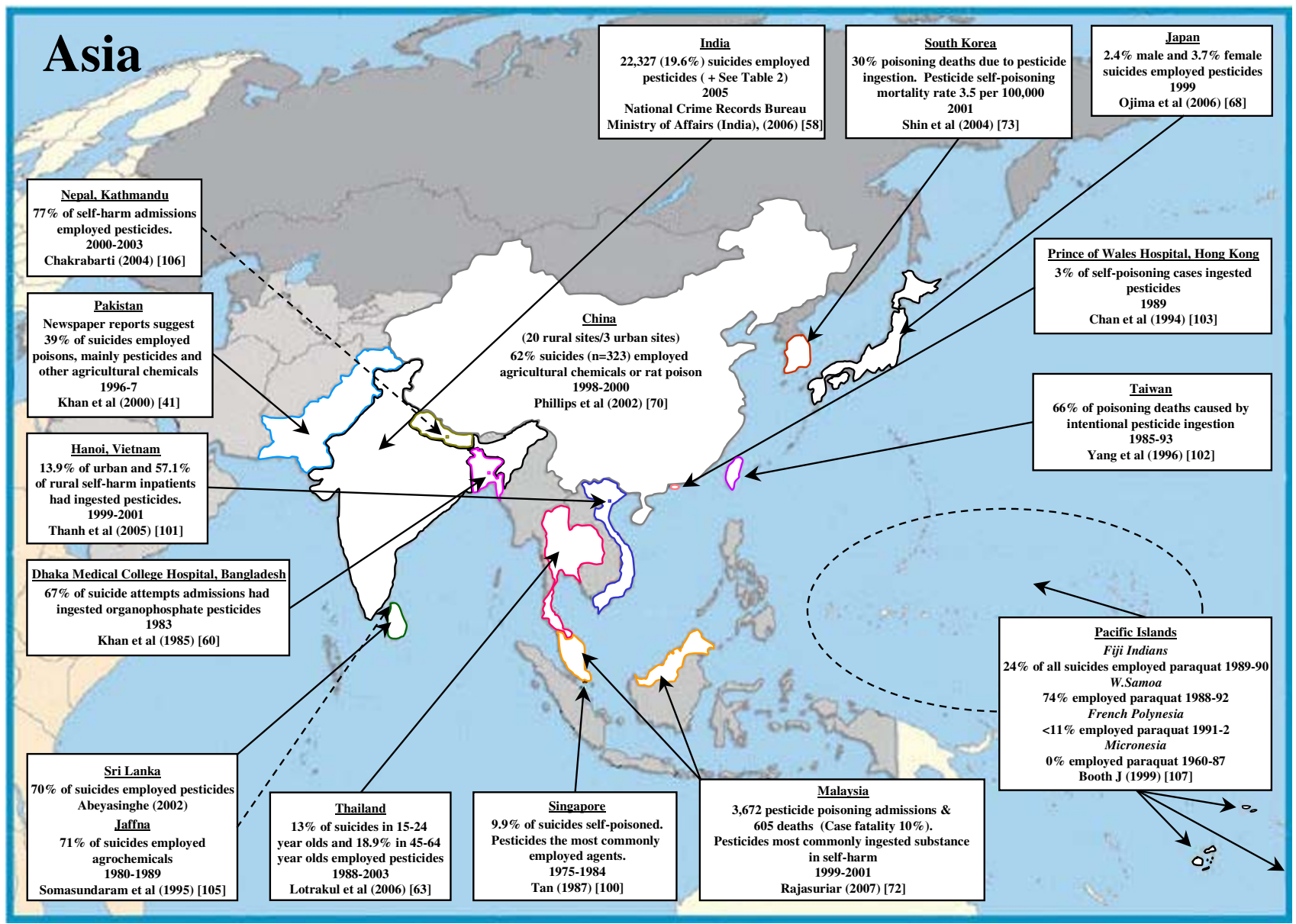

Figure 5

Pesticide suicides in South East Asia and Western Pacific regions.

The estimated proportion of suicides attributable to pesticide self-poisoning varies considerably across the WHO's six regions: in Europe we estimate $3.7 \%$ of suicides employ pesticides, the Americas: $4.9 \%$, Eastern Mediterranean: $16.5 \%$, Africa: $22.9 \%$, South East Asia: $20.7 \%$ and Western Pacific: $55.8 \%$.

Whilst our estimate of pesticide deaths is similar to that of 300,000 given in recent reviews $[6,7]$, this is the first time an attempt has been made to estimate the number of pesticide self-poisoning using data from all six WHO regions. Our review indicates that previous crude extrapolations based on data from a limited number of countries have provided a relatively robust estimate of the extent of the problem. Pesticide poisoning and hanging are the two most commonly used methods of suicide worldwide, though precise data on their relative frequency are lacking. An important difference between suicides using these two methods is that deaths from pesticide self-poisoning are considerably more amenable than those from hanging to prevention by both restricting access to pesticides and improving the medical management of pesticide poisoning.

The number of deaths from pesticide self-poisoning under-estimates the true burden on health services of pesticide related self-harm[75]. Acts of pesticide self-poisoning are associated with a case fatality of between $1 \%$ and $70 \%$, depending on the particular pesticide taken. Paraquat and aluminium phosphide self-poisoning have case-fatality in excess of $70 \%[11,12]$ whereas case fatality for the organophosphorus (OP) insecticides dimethoate and chlorpyrifos are $23 \%$ and $8 \%$ respectively [76]. Based on the crude assumption that overall case fatality following pesticide self-poisoning worldwide is between $10 \%$ (based on estimated case fatality in China, personal com- 
Table 2: Estimates of suicide rates and the contribution of pesticides to suicide in India

\begin{tabular}{|c|c|c|c|c|}
\hline Author & $\begin{array}{l}\text { Years covered } \\
\text { (no. suicides) }\end{array}$ & Setting & $\begin{array}{l}\text { Estimated total (all } \\
\text { methods) suicide rate }\end{array}$ & $\begin{array}{l}\text { Estimates of the proportion of } \\
\text { suicides (or episodes of self- } \\
\text { harm) due to pesticides }\end{array}$ \\
\hline \multirow[t]{2}{*}{ Nandi et al. [89] } & $1976-7(n=101)$ & $\begin{array}{l}\text { Districts in West Bengal } \\
\text { (rural) }\end{array}$ & $\begin{array}{l}\text { Daspur area: } 29 \text { per } \\
100,000\end{array}$ & $58 \%$ due to endrin (a pesticide) \\
\hline & & & $\begin{array}{l}\text { Chandrakona area: } 5 \text { per } \\
100,000\end{array}$ & $37 \%$ due to endrin \\
\hline Bannerjee et al. [90] & $1978(n=58)$ & $\begin{array}{l}\text { Villages in Deganga, West } \\
\text { Bengal (rural) }\end{array}$ & 43 per 100,000 & $\begin{array}{l}93 \% \text { suicides due to self-poisoning } \\
\text { ("almost exclusively)" } \\
\text { organophosphorus pesticides }\end{array}$ \\
\hline Shukla et al. [9I] & $1986-7(n=187)$ & $\begin{array}{l}\text { Jhansi City, Uttar Pradesh } \\
\text { (urban) }\end{array}$ & 29 per 100,000 & $10 \%$ (insecticides and rat poison). \\
\hline Bhatia et al. [92] & Not stated $(n=55)$ & $\begin{array}{l}\text { Delhi (urban and rural } \\
\text { areas) }\end{array}$ & - & $\begin{array}{l}\text { Only 13\% of suicides had self- } \\
\text { poisoned (all substances) }\end{array}$ \\
\hline Joseph et al. [64] & $1994-9(n=609)$ & $\begin{array}{l}\text { Villages in Kaniyambadi } \\
\text { (rural), Tamil Nadu }\end{array}$ & 95 per 100,000 & $\begin{array}{l}45 \% \text { self-poisoning (all substances). } \\
40 \% \text { of the suicides in } 15-19 \text { year } \\
\text { olds used pesticides in 1992-2001 } \\
\text { [93] }\end{array}$ \\
\hline Lalwani et al. [94] & $199 \mid-2000(n=222)$ & New Delhi (urban) & - & $\begin{array}{l}\text { I0-18 year olds: poisoning } \\
\text { accounted for } 49 \% \text { of male and } 37 \% \\
\text { female suicides. Pesticides were } \\
\text { commonest poisons recorded. }\end{array}$ \\
\hline Gururaj et al. [95] & $2001-2(n=269)$ & Bangalore (urban) & - & $\begin{array}{l}28 \% \text { (male) and 19\% (female) } \\
\text { suicides were self-poisoning (all } \\
\text { substances). }\end{array}$ \\
\hline Kumar et al. [96] & $1994-2004(n=44 \mid)$ & Mannipal (rural) & - & $>55 \%$ insecticides \\
\hline Prasad et al. [65] & $2000-2002(n=306)$ & $\begin{array}{l}\text { Villages in Kaniyambadi } \\
\text { (rural), Tamil Nadu }\end{array}$ & 92 per 100,000 & $\begin{array}{l}\text { Organophosphorus pesticides } \\
\text { accounted for } 40.5 \% \text { of suicides }\end{array}$ \\
\hline Mohanty et al. [97] & $2000-2003(n=588)$ & $\begin{array}{l}\text { Berhampur (rural and } \\
\text { urban) }\end{array}$ & - & $\begin{array}{l}30.6 \% \text { of all suicides were self- } \\
\text { poisoning ( }>70 \% \text { used pesticides) }\end{array}$ \\
\hline Bose et al. [66] & $1998-2004(n=638)$ & $\begin{array}{l}\text { Villages in Kaniyambadi } \\
\text { (rural), Tamil Nadu }\end{array}$ & 82 per 100,000 & $40 \%$ poisoning (majority pesticides) \\
\hline Sharma et al. [98] & $1996-2005(n=1421)$ & $\begin{array}{l}\text { Chandigarh (rural and } \\
\text { urban) }\end{array}$ & - & $\begin{array}{l}\text { Aluminium phosphide accounts for } \\
24 \% \text { of all suicides; } \\
\text { organophosphorus and } \\
\text { organochlorine products } 10 \%\end{array}$ \\
\hline Gajalakshmi et al. [67] & $1997-8(n=3,249)$ & $\begin{array}{l}\text { Villpuram district (rural), } \\
\text { Tamil Nadu }\end{array}$ & 62 per 100,000 & $\begin{array}{l}53 \% \text { self-poisoning ("generally } \\
\text { involved agrochemicals") }\end{array}$ \\
\hline Kumar P et al. [99] & $200 \mathrm{I}$ and $2005(\mathrm{n}=200)$ & Six districts in rural Punjab & $\begin{array}{l}\text { 12.4 per } 100,000(2001) \\
13.1 \text { per } 100,000(2005)\end{array}$ & $\begin{array}{l}\text { Pesticide/poison used in } 77 \% \text { ( } 154 / \\
200 \text { ) suicides studied. }\end{array}$ \\
\hline
\end{tabular}

Reasonable estimate of Indian suicide rate from these data: 40 per 100,000 (lower limit: 10 per 100,000 Indian Police Statistics [58]); upper limit 80 per 100,000 Tamil Nadu [64] [65] [66] [67].

munication Michael Phillips) and 20\% (based on data from India [30\% case fatality, Table 2] and Malaysia $16 \%[72])$, our conservative estimate of 258,234 pesticide deaths arise from between 1,291,170 and 2,582,340 episodes of pesticide self-poisoning annually.

OP insecticides appear to be the most commonly ingested pesticides in rural Asia, accounting for around two thirds of cases[77]. Depending on the particular OP ingested, around $20-30 \%$ of patients require intubation $[78,79]$. Two-thirds of intubated patients will be intubated for a median of 45 hours post admission. One third of intubated patients will develop late respiratory failure (intermediate syndrome) requiring intubation for a median of 284 hours [79]. As a result, across rural Asia, intensive care units are often filled with OP poisoned patients on ventilators, preventing the admission of other acutely ill patients $[80,75]$. Relatively few $(<10 \%)$ of those poisoned with other pesticides require intubation. Patients ill with paraquat or aluminium phosphide poisoning are usually not intubated or admitted to intensive care because of their poor prognosis. These figures allow us to generate a crude estimate of person days of ventilation required each year of $1,147,000$ to $2,294,000$ days based on the high and low estimates of the number of episodes of pesticide self-poisoning (see Additional file 1 for details). This would require the constant use of 3,140 to 6,280 ventilators worldwide solely for managing self-poisoning with pesticides. But ventilators are not available in many parts of the developing world so lack of access to ventilators 
makes a substantial contribution to deaths from pesticide ingestion. Furthermore, the use of ventilators, where these are available, for cases of pesticide poisoning will compromise the capacity of hospitals to manage other life threatening conditions.

The global distribution of fatal pesticide self-poisoning does not mirror pesticide sales. The largest sales $(29 \%$ of the world market) are in Europe [81] which accounted for only $2 \%(6,080 / 258,234)$ of pesticide suicides (Table 1$)$. In contrast, Asia (comprising the Western Pacific and SE Asia regions in Table 1) accounts for approximately 25\% of the world market [81] but $91 \%(235,620 / 258,234)$ of deaths [81]. This is probably due to the different agricultural practices in these regions - the large number of small holders practising agriculture in Asia allows easy access to pesticides, while the very restricted number of people working the land in Western countries means that few people are able to obtain pesticides in the quantities and strength that farmers use. Of note, the greatest market growth in pesticide sales is in Africa and the Middle East with a $9.1 \%$ rise in sales between 2004 and 2005[81] - so there may be a corresponding growth in pesticide selfharm in these regions in years to come.

\section{Limitations}

The main limitation of this review is the absence of good quality cause-specific suicide mortality data for a number of the world's largest countries - most notably Indonesia, Iran, Russia, Germany and Ethiopia. Missing data from Europe are less problematic than data from Africa and the Eastern Mediterranean, as estimates for these latter regions are based on particularly limited data. Nevertheless, less than $10 \%$ of the world's suicides come from these areas. The availability of better quality data from these regions is therefore unlikely to greatly affect our estimates, unless the overall number of suicides in these regions has been grossly under-estimated. Our figures might be further refined through requests for pesticide mortality data from individual governments and hand searches of the grey literature.

The second limitation is in relation to the likely poor quality of India's suicide mortality data. India is the second largest country in the world, contributing almost $20 \%$ to the world's population. In a sensitivity analysis we used plausible estimates for suicide rates and the contribution of pesticides to suicide in India. This analysis resulted in an increase of our estimate of pesticide deaths to 371,594 - an increase of around 110,000 deaths. Obtaining nationally representative data on suicide rates, and the contribution of pesticide suicides to suicides in India, should be a priority for health funding agencies over the next decade. Poor quality data from other parts of the world are also likely to result in under-estimations.
This is particularly the case as most pesticide suicides occur in rural (farming) districts where the quality of suicide data collection is likely to be poorer than in urban locations. Thirdly, we have no strong evidence that the proportion of pesticide suicides in countries within WHO mortality strata for each region is the same; mortality patterns are a crude marker of agricultural practices and the availability of toxic pesticides. Fourthly, in some instances the data obtained from the literature predated WHO's 2002 estimate of world suicides by up to 20 years e.g. figures for Nigeria were based on data for 1979-1988[22] and for Ireland for 1982-1994 [47]. Changes in the use of pesticides for self-harm may have resulted in us under- or over-estimating pesticide suicides within particular strata. Lastly, some of our estimates for pesticide suicides are based on combined accidental and suicide deaths; but where such deaths are separately categorised, the great majority of pesticide deaths are suicides so it is unlikely that conflating intentional and unintentional pesticide deaths in these countries would substantial alter the overall results $[82,38]$.

\section{Policy options for reducing pesticide suicides}

Pleas for national and international action to restrict the sale of pesticides to reduce their impact on human health date back over 40 years. In 1966 Ganapathi and colleagues wrote in the Journal of the Indian Medical Association "The present authors plead for a restriction in the sale of such lethal agents. It is hoped that a considerable number of young lives could then be saved from such a measure.... [83]."

In 2005 WHO launched a global initiative to tackle the burden of pesticide suicides[84]. Inactivity prior to this is likely to reflect the tensions between the perceived benefits of pesticides in increasing crop yields in low-income countries, where under-nutrition is an important contributor to poor health, and concern about the health effects of excessive exposure. Over the years the pesticide industry has responded to safety concerns with a number of initiatives to reduce the global death toll from pesticide poisoning. However, the pesticide industry is highly profitable - global sales of pesticides amounted to $\$ 31$ billion in 2005[81] - and there are clear conflicts of interest where such initiatives may compromise profits. Industry led initiatives are to be welcomed, but national and international health policy makers should recognise that they may not focus on those aspects of the problem most likely to reduce mortality [85].

Restricting access to the most toxic pesticides is of paramount importance to reduce the number of severe selfpoisoning episodes[86]. National policies and systems for enforcement need to be put in place immediately to phase out WHO Class I and the most toxic Class II pesticides. 
Likewise, in the longer-term, cost-effective alternatives have to be made available to farmers to reduce the overall use of pesticides. Further investments are needed to promote the safe storage of pesticides at community level. To further reduce the case-fatality from pesticide self-harm investments are needed to improve quality, affordability and accessibility of health care close to the affected communities [87]. A feature of pesticide suicides is that many patients reach hospital alive, providing opportunities for resuscitation. Data from China indicate that almost two thirds of pesticide deaths received some resuscitation that failed - improved training and resources for medical care may have prevented a number of these deaths[88]. Likewise, research and investments are needed to support community and facility based interventions aimed at reducing the incidence of self-harm overall. Such interventions need to be based upon policies and strategies that give due consideration to local culture, patterns of self-harm and institutional frameworks and not just a transfer of strategies from Europe or North America.

\section{Conclusion}

Fatality estimates such as we have presented here underrepresent the burden of disease because suicide has a long term impact on family, friends and work colleagues of the deceased. Furthermore, as we have shown, pesticide poisoning occurs predominantly in rural areas of low income countries, and the intense medical care required to treat pesticide poisoned patients may impact greatly on already stretched healthcare resources. By any measure, the burden of pesticide poisoning is large and merits urgent policy attention. However, attempts to prevent suicide in these areas and WHO's global suicide prevention strategy are largely modelled on findings from research and models of suicide prevention developed in the West. Research undertaken in low income communities - particularly in rural areas - is urgently required to provide the evidence base to underpin public health strategies for preventing pesticide suicides in these countries.

\section{Competing interests}

DG and ME, are on the scientific advisory group of a Syngenta-funded study to assess the toxicity of a new formulation of paraquat, and have received travel expenses to attend research group meetings.

\section{Authors' contributions}

DG had the idea for the study and developed the methodology and approaches to synthesis of the data jointly with ME, FK and MP. DG carried out the literature searching and wrote the first draft of the paper. All authors provided critical comments and were involved in re-drafting the manuscript. DG is guarantor.

\section{Additional material}

\section{Additional file 1}

Method used to estimate worldwide ventilator occupancy as a result of pesticide self-poisoning. This provides the calculations behind the estimates of ventilator use in paragraph 5 of the discussion section of the paper. Click here for file

[http://www.biomedcentral.com/content/supplementary/1471-

2458-7-357-S1.doc]

\section{Acknowledgements}

Mrs Jacky Tonkin for creating the maps. Dr Paulo Menezes for identifying sources of Brazilian suicide data. Prof Nick Buckley and Dr Alexandra Fleischmann for helpful comments on an earlier draft.

\section{References}

I. World Health Report 2004. WHO, Geneva; 2004.

2. Taylor SJ, Kingdom D, Jenkins R: How are nations trying to prevent suicide? An analysis of national suicide prevention strategies. Acta Psychiatr Scand 1997, 95:457-463.

3. Hawton K: Restriction of access to methods of suicide as a means of suicide prevention. In Prevention and treatment of suicidal behaviour from Science to practice Edited by: Hawton K. Oxford: Oxford University Press; 2005:279-291.

4. Conner KR, Phillips MR, Meldrum S, Knox KL, Zhang Y, Yang G: Low-planned suicides in China. Psychol Med 2005, 35: I I 97-I 204.

5. Jeyaratnam J: Health problems of pesticide usage in the Third World. Br J Ind Med 1985, 42:505-506.

6. Gunnell D, Eddleston M: Suicide by intentional ingestion of pesticides: a continuing tragedy in developing countries. Int J Epidemiol 2003, 32:902-909.

7. Buckley NA, Karalliedde L, Dawson A, Senanayake N, Eddleston M Where is the evidence for treatments used in pesticide poisoning? Is clinical toxicology fiddling while the developing world burns? I Toxicol Clin Toxicol 2004, 42: I I3- I I6.

8. Bertolote JM, Fleischmann A, Butchart A, Besbelli N: Suicide, suicide attempts and pesticides: a major hidden public health problem. Bull World Health Organ 2006, 84:260.

9. Gunnell D, Ho D, Murray V: Medical management of deliberate drug overdose - a neglected area for suicide prevention? Emergency Medical Journal 2004, 2 I:35-38.

10. Eddleston M, Sudarshan K, Senthilkumaran M, Reginald K, Karalliedde L, Senarathna L, de Silva D, Rezvi Sheriff MH, Buckley NA, Gunnell D: Patterns of hospital transfer for self-poisoned patients in rural Sri Lanka? Implications for estimating the incidence of self-poisoning acts in the developing world. Bull World Health Organ 2006, 84:276-282.

II. Fitzgerald GR, Barniville G, Flanagan M, Silke B, Carmody M, O'Dwyer WF: The changing pattern of paraquat poisoning: an epidemiologic study. Ir Med J 1978, 71:103-108.

12. Chugh SN, Dushyant, Ram S, Arora B, Malhotra KC: Incidence \& outcome of aluminium phosphide poisoning in a hospital study. Indian J Med Res 1991, 94:232-235.

13. Kinyanda E, Hjelmeland H, Musisi S: Deliberate self-harm as seen in Kampala, Uganda - a case-control study. Soc Psychiatry Psychiatr Epidemiol 2004, 39:318-325.

14. arap Mengech HN, Dhadphale M: Attempted suicide (parasuicide) in Nairobi, Kenya. Acta Psychiatr Scand 1984, 69:4 I6-4I9.

15. Eferakeya AE: Drugs and suicide attempts in Benin City, Nigeria. Br J Psychiatry 1984, I45:70-73.

16. Odejide AO, Williams AO, Ohaeri JU, Ikuesan BA: The epidemiology of deliberate self-harm. The Ibadan experience. $\mathrm{Br} J \mathrm{Psy}$ chiatry 1986, I49:734-737.

17. Obembe A, llechukwu STC, Tunwashe OL, Odukoya O: Self poisoning as seen in Lagos University Teaching Hospital: A Four Year Review. The Nigerian Medical Practitioner I 986, I I:49-53.

18. Nhachi CF, Kasilo OM: The pattern of poisoning in urban Zimbabwe. J Appl Toxicol 1992, I 2:435-438. 
19. Tagwireyi D, Ball DE, Nhachi CF: Poisoning in Zimbabwe: a survey of eight major referral hospitals. J Appl Toxicol 2002, 22:99-105.

20. Bahta $Y$, Fikreyesus $Y$ : Analysis of admissions to the medical intensive care unit of a teaching hospital in Addis Ababa. Ethiop Med J 1988, 26:61-67.

21. Abebe M: Organophosphate pesticide poisoning in 50 Ethiopian patients. Ethiop Med J 1991, 29:109-I I8.

22. Nwosu SO, Odesanmi WO: Pattern of suicides in Ile-Ife, Nigeria. West Afr J Med 200I, 20:259-262.

23. Scribante L, Blumenthal R, Saayman G, Roos JL: A retrospective review of 1018 suicide cases from the capital city of South Africa for the period 1997-2000. Am J Forensic Med Pathol 2004, 25:52-55.

24. Ndosi NK, Mbonde MP, Lyamuya E: Profile of suicide in Dar es Salaam. East Afr Med J 2004, 81:207-2II.

25. Dzamalala CP, Milner DA, Liomba NG: Suicide in Blantyre, Malawi (2000-2003). J Clin Forensic Med 2006, I 3:65-9.

26. Langley R, Sumner D: Pesticide mortality in the United States 1979-1 998. Vet Hum Toxicol 2002, 44:10I-I05.

27. Pan American Epidemiological Association: Epidemiological Situation of Acute Pesticide Poisoning in the Central American Isthmus, 1992 - 2000. Epidemiol Bull 2002, 23: I-8.

28. Puentes-Rosas E, Lopez-Nieto L, Martinez-Monroy T: [Mortality from suicides: Mexico, 1990-200I]. Rev Panam Salud Publica 2004, I 6:102-109.

29. Tinoco R, Tinoco R, Parsonnet J, Halperin D: Paraquat poisoning in southern Mexico: a report of $\mathbf{2 5}$ cases. Arch Environ Health 1993, 48:78-80.

30. Mahy G: Completed suicide in Barbados. West Indian Med J 1987 , 36:91-94.

31. Hutchinson G, Daisley H, Simeon D, Simmonds V, Shetty M, Lynn D: High rates of paraquat-induced suicide in southern Trinidad. Suicide Life Threat Behav 1999, 29:186-191.

32. Escoffery CT, Shirley SE: Fatal poisoning in Jamaica: a coroner's autopsy study from the University Hospital of the West Indies. Med Sci Law 2004, 44: I 16-120.

33. [http://tabnet.datasus.gov.br]. http://tabnet.datasus.gov.br Accessed $5 / 1 / 2007$.

34. Werneck GL, Hasselmann MH, Phebo LB, Vieira DE, Gomes VL: [Suicide attempts recorded at a general hospital in Rio de Janeiro, Brazil.]. Cad Saude Publica 2006, 22:2201-2206.

35. Cole DC, Carpio F, Leon N: Economic burden of illness from pesticide poisonings in highland Ecuador. Rev Panam Salud Publica 2000, 8: 196-201.

36. Graafsma T, Kerkhof A, Gibson D, Badloe R, van de Beek LM: High rates of suicide and attempted suicide using pesticides in Nickerie, Suriname, South America. Crisis 2006, 27:77-8I.

37. Jors E, Morant RC, Aguilar GC, Huici O, Lander F, Baelum J, Konradsen $\mathrm{F}$ : Occupational pesticide intoxications among farmers in Bolivia: a cross-sectional study. Environ Health 2006, 5: 10.

38. Abdullat EM, Hadidi MS, Alhadidi N, Al-Nsour TS, Hadidi KA: Agricultural and horticultural pesticides fatal poisoning; the Jordanian experience 1999-2002. J Clin Forensic Med 2006 13:304-307.

39. Moghadamnia AA, Abdollahi M: An epidemiological study of poisoning in Northern Islamic Republic of Iran. Eastern Mediterranean Health Journal 2002, 8:550-5.

40. Abdollahi M, Jalali N, Sabzevari O, Hoseini R, Ghanea T: A retrospective study of poisoning in Tehran. Clinical Toxicology 1997, 35:387-393.

4l. Khan MM, Reza $\mathrm{H}$ : The pattern of suicide in Pakistan. Crisis 2000, 2 I:3 |-35.

42. Khan MM, Reza $\mathrm{H}$ : Gender differences in nonfatal suicida behavior in Pakistan: significance of sociocultural factors. Suicide Life Threat Behav 1998, 28:62-68.

43. Saeed A, Bashir MZ, Khan D, labal J, Raja KS, Rehman A: Epidemiology of suicide in Faisalabad. Journal of Ayub Medical College Abbottabad 2002, 14:34-37.

44. Okasha A, Lotaif F: Attempted suicide. An Egyptian investigation. Acta Psychiatr Scand 1979, 60:69-75.

45. Michel K, Ballinari P, Bille-Brahe U, Bjerke T, Crepet P, De Leo D, Haring C, Hawton K, Kerkhof A, Lonnqvist J, Querejeta I, SalanderRenberg E, Schmidtke A, Temesvary B, Wasserman D: Methods used for parasuicide: results of the WHO/EURO Multicentre
Study on Parasuicide. Soc Psychiatry Psychiatr Epidemiol 2000, 35:156-163.

46. Thompson JP, Casey PB, Vale JA: Deaths from pesticide poisoning in England and Wales I990-199I. Hum Exp Toxicol 1995, I 4:437-445.

47. Daeid NN: Suicide amongst the agricultural sector in Ireland; 1982-1994. Journal of the Irish Colleges of Physicians and Surgeons 1997, 26:180-182

48. Persson H, Palmborg M, Irestedt B, Westberg U: Pesticide poisoning in Sweden - actual situation and changes over a 10-year period. Przeglad Lekarski 1997, 54:657-66I.

49. Tziafeta SG, Karampelas NA, Papadimitriou E, Ske-parni F: Toxicological aspects of sudden and violent deaths in Southwestern Greece: A three-year review (200I-2003). Review of Clinical Pharmacology and Pharmacokinetics, International Edition 2004, I 8: 184-185.

50. Vougiouklakis T, Boumba VA, Mitselou A, Peschos D, Gerontopoulos $\mathrm{K}$ : Trends in suicide mortality in the deprived region of Epirus (north-west Greece) during the period 1998-2002. Med Sci Law 2005, 45:39-46.

5I. Parron T, Hernandez AF, Villanueva E: Increased risk of suicide with exposure to pesticides in an intensive agricultural area. A 12-year retrospective study. Forensic Sci Int 1996, 79:53-63.

52. Azmak AD: Suicides in Trakya region, Turkey, from 1984 to 2004. Med Sci Law 2006, 46:19-30.

53. Przybylska A: [Poisoning caused by chemicals for plant protection in Poland in 2001]. Przegl Epidemiol 2003, 57:107-116.

54. Przybylska A: [Poisoning caused by chemicals for plant protection in Poland in 2002]. Przegl Epidemiol 2004, 58: I I I-I2I.

55. Fabritius K, Balasescu M: Acute non-occupational intoxications with pesticides in Romania: a comparative study from $\mathbf{I 9 8 8}$ to 1993. Toxicol Lett 1996, 88:21|-214

56. Iliev Y, Akabaliev V, Doychinov I: Characteristics of adult acute poisoning mortality in a large industrial-agrarian region of Bulgaria during socioeconomic transition and crisis (19901998). Vet Hum Toxicol 2000, 42:366-369.

57. Berecz R, Caceres M, Szlivka A, Dorado P, Bartok E, Penas-LLedo E, Llerena $A$, Degrell I: Reduced completed suicide rate in Hungary from 1990 to $200 \mathrm{I}$ : relation to suicide methods. J Affect Disord 2005, 88:235-238.

58. Accidental Deaths and Suicides in India 2005 New Delhi: National Crime Records Bureau Ministry of Affairs; 2006.

59. WHO: Mental Health and Substance Abuse Facts and Figures Suicide Prevention: Emerging from Darkness South East Asia: WHO; 2007.

60. Khan N: Poisoning in a medical unit of Dhaka Medical College Hospital in 1983. Bangladesh Medical Journal I985, I4:9-I2.

6I. Heijnen H: WHO Bangladesh: International Programme OnChemical Safety. 200I.

62. Mode of Suicides - 20052005 [http://www.police.lk/divisions/ crime/mode suicides 2005.html].

63. Lotrakul M: Suicide in Thailand during the period I998-2003. Psychiatry Clin Neurosci 2006, 60:90-95.

64. Joseph A, Abraham S, Muliyil JP, George K, Prasad J, Minz S, Abraham $\mathrm{VJ}$, Jacob KS: Evaluation of suicide rates in rural India using verbal autopsies, 1994-9. BM/ 2003, 326: I I 2I-I I 22.

65. Prasad J, Abraham VJ, Minz S, Abraham S, Joseph A, Muliyil JP, George K, Jacob KS: Rates and factors associated with suicide in Kaniyambadi Block, Tamil Nadu, South India, 2000-2002. Int J Soc Psychiatry 2006, 52:65-7I.

66. Bose A, Konradsen F, John J, Suganthy P, Muliyil J, Abraham S: Mortality rate and years of life lost from unintentional injury and suicide in South India. Trop Med Int Health 2006, I I: I 553-I 556.

67. Gajalakshmi V, Peto R: Suicide rates in rural Tamil Nadu, South India: Verbal autopsy of 39000 deaths in 1997-98. Int J Epidemiol 2007.

68. Ojima T, Nakamura Y, Detels R: Comparative study about methods of suicide between Japan and the United States. I Epidemiol 2004, I 4: 187-192.

69. Phillips MR, Yang GH: Suicide and attempted suicide in China, | 990-2002. MMWR 2004, 53:48|-484.

70. Phillips MR, Yang G, Zhang Y, Wang L, Ji H, Zhou M: Risk factors for suicide in China: a national case-control psychological autopsy study. Lancet 2002, 360:1728-1736.

71. Maniam T: Suicide and parasuicide ina hill resort in Malaysia. $\mathrm{Br}$ J Psychiatry 1988, I 53:222-225. 
72. Rajasuriar R, Awang R, Hashim SB, Rahmat HR: Profile of poisoning admissions in Malaysia. Hum Exp Toxicol 2007, 26:73-8I.

73. Shin SD, Suh GJ, Rhee JE, Sung J, Kim J: Epidemiologic characteristics of death by poisoning in |99|-200| in Korea. J Korean Med Sci 2004, I 9:186-194.

74. Phillips MR, Li X, Zhang Y: Suicide rates in China, 1995-99. Lancet 2002, 359:835-840.

75. Eddleston $M$, Sheriff $M H$, Hawton K: Deliberate self harm in Sri Lanka: an overlooked tragedy in the developing world. $B M$ J 1998, 3 17:133-135.

76. Eddleston M, Eyer P, Worek F, Mohamed F, Senarathna L, von Meyer L, Juszczak E, Hittarage A, Azhar S, Dissanayake W, Sheriff MH, Szinicz L, Dawson AH, Buckley NA: Differences between organophosphorus insecticides in human self-poisoning: a prospective cohort study. Lancet 2005, 366: | 452-I459.

77. Eddleston M: Patterns and problems of deliberate self-poisoning in the developing world. OIM 2000, 93:7I5-73I.

78. Srinivas RC, Venkateswarlu V, Surender T, Eddleston M, Buckley NA Pesticide poisoning in south India: opportunities for prevention and improved medical management. Trop Med Int Health 2005, I 0:58I-588.

79. Eddleston M, Mohamed F, Davies JO, Eyer P, Worek F, Sheriff MH, Buckley NA: Respiratory failure in acute organophosphorus pesticide self-poisoning. QJM 2006, 99:5I3-522.

80. Kamat SR, Heera S, Potdar PV, Shah SV, Bhambure NM, Mahashur AA: Bombay experience in intensive respiratory care over 6 years. J Postgrad Med 1989, 35:123-134.

81. CropLife International Annual Report 2005/6. Belgium: Croplife International; 2006.

82. Nesime Y, Lokman B, Akif IM, Gurol C, Basar C, Mustafa K: Acute pesticide poisoning related deaths in Turkey. Vet Hum Toxicol 2004, 46:342-344.

83. Ganapathi MN, Rao AV: A study of suicide in Madurai. J Indian Med Assoc 1966, 46: 18-23.

84. World Health Organization and IASP International Association for Suicide Prevention: Safer Access to Pesticides: Community Interventions Geneva: Management of Mental and Brain Disorders, Department of Mental Health and Substance Abuse World Health Organization; 2006.

85. Konradsen F, Dawson AH, Eddleston M, Gunnell D: Pesticide selfpoisoning: thinking outside the box. Lancet 2007, 369:169-170.

86. Konradsen F, van der Hoek W, Cole DC, Hutchinson G, Daisley H, Singh S, Eddleston M: Reducing acute poisoning in developing countries - options for restricting the availability of pesticides. Toxicology 2003, 192:249-261.

87. Eddleston M, Buckley NA, Gunnell D, Dawson AH, Konradsen F: Identification of strategies to prevent death after pesticide self-poisoning using a Haddon matrix. Inj Prev 2006, 1 2:333-337.

88. Yang GH, Phillips MR, Zhou MG, Wang LJ, Zhang YP, Xu D: Understanding the unique characteristics of suicide in China: national psychological autopsy study. Biomed Environ Sci 2005, 1 8:379-389.

89. Nandi DN, Mukherjee SP, Banerjee G, Ghosh A, Boral GC, Chowdury $A$, Bose $\mathrm{J}$ : Is suicide preventable by restricting the availability of lethal agents ? A rural survey of West Bengal. Indian Journal of Psychiatry 1979, 2 I:25 I-255.

90. Banerjee G, Nandi DN, Nandi S, Sarkar S, Boral GC, Ghosh A: The vulnerability of Indian women to suicide a field-study. Indian Journal of Psychiatry 1990, 32:305-308.

91. Shukla GD, Verma BL, Mishra DN: Suicide in Jhansi City. Indian Journal of Psychiatry 1990, 32:44-5I.

92. Bhatia MS, Aggarwal NK, Aggarwal BB: Psychosocial profile of suicide ideators, attempters and completers in India. Int / Soc Psychiatry 2000, 46:155-163.

93. Aaron R, Joseph A, Abraham S, Muliyil J, George K, Prasad J, Minz S: Suicides in young people in rural southern India. Lancet 2004, 363: III7-8.

94. Lalwani S, Sharma GS, Kabra SK, Girdhar S, Dogra TD: Suicide among children and adolescents in South Delhi (I99|-2000). Indian J Pediatr 2004, 71:701-703.

95. Gururaj G, Isaac MK, Subbakrishna DK, Ranjani R: Risk factors for completed suicides: a case-control study from Bangalore, India. Inj Control Saf Promot 2004, I I: |83-191.
96. Kumar TS, Kanchan T, Yoganarasimha K, Kumar GP: Profile of unnatural deaths in Manipal, Southern India I994-2004. J Clin Forensic Med 2006, I3: I I7-120.

97. Mohanty S, Sahu G, Mohanty MK, Patnaik M: Suicide in India - A four year retrospective study. J Clin Forensic Med 2006.

98. Sharma BR, Gupta M, Sharma AK, Sharma S, Gupta N, Relhan N, et al.: Suicides in Northern India: Comparison of trends and review of literature. J Clin Forensic Med 2006.

99. Kumar P, Sharma SL: Suicides in rural Punjab Punjab: Institute for Development and Communication (IDC); 2006.

100. Tan CT: Suicidal poisoning deaths in Singapore 1975-1984. Ann Acad Med Singapore 1987, 1 6:300-302.

I0I. Thanh HT, Jiang GX, Van TN, Minh DP, Rosling H, Wasserman D: Attempted suicide in Hanoi, Vietnam. Soc Psychiatry Psychiatr Epidemiol 2005, 40:64-7I.

102. Yang CC, Wu JF, Ong HC, Hung SC, Kuo YP, Sa CH, Chen SS, Deng JF: Taiwan National Poison Center: epidemiologic data I9851993. J Toxicol Clin Toxicol 1996, 34:65I-663.

103. Chan TY, Critchley JA: Hospital admissions due to acute poisoning in the New Territories, Hong Kong. Southeast Asian J Trop Med Public Health 1994, 25:579-582.

104. Somasundaram DJ, Rajadurai S: War and suicide in northern Sri Lanka. Acta Psychiatr Scand 1995, 9 I: |-4

105. Abeyasinghe R: Psychiatric aspects of pesticide poisoning. In Pesticides: Health Impacts and Alternatives Proceedings of a workshop held in Colombo 24 January 2002 Edited by: Smit LAM. Working Paper 45, I2-I5. Sri Lanka, International Water Management Institute; 2002.

106. Chakrabarti K, Devkota KC: Retrospective study of suicide cases admitted in Nepal Medical College Teaching Hospital. Nepal Med Coll J 2004, 6: I I6-I I8.

107. Booth $\mathrm{H}$ : Pacific Island suicide in comparative perspective. Biosoc Sci 1999, 3 I:433-448.

108. [http://www.who.int/whosis/en/index.html]. accessed I7/08/2007

\section{Pre-publication history}

The pre-publication history for this paper can be accessed here:

\section{http://www.biomedcentral.com/1471-2458/7/357/pre} pub
Publish with Bio Med Central and every scientist can read your work free of charge

"BioMed Central will be the most significant development for disseminating the results of biomedical research in our lifetime. "

Sir Paul Nurse, Cancer Research UK

Your research papers will be:

- available free of charge to the entire biomedical community

- peer reviewed and published immediately upon acceptance

- cited in PubMed and archived on PubMed Central

- yours - you keep the copyright
BioMedcentral 